\title{
The effect of combinations of cyproconazole and fludioxonil on infestation of wheat and barley grains
}

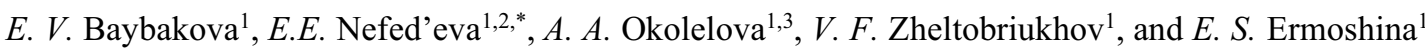 \\ ${ }^{1}$ Volgograd State Technical University, Industrial Ecology and Safety Department, Volgograd, 400005 Russia \\ ${ }^{2}$ Volgograd State University, Biology Department, Volgograd, 400062 Russia \\ ${ }^{3}$ Volgograd State Agrarian University, Soil science and General biology Department, Volgograd, 400002 Russia
}

\begin{abstract}
The most popular and affordable means to protect plants from fungal diseases are fungicides. Development of new products is aimed at preparation of the composition of several substances to achieve the effect of mutual enhancement of action. We used the grains of wheat (Triticum $s p$. variety Julius) and barley (Hordeum sativum variety Gloria), they were significantly infected with phytopathogenic fungi, which allows us to get reliable data on the effectiveness of active substances of fungicides. All wheat grains treated with fungicides were infected less than the control ones. Analysis of the effect of individual fungicides demonstrated that the fungi were more sensitive to fludioxonil, especially at doses of CF $0: 2$ (56.7\% of infected grains) and CF 0:4 (36.7\% of infected grains) 5.0 and $10.0 \mathrm{~g} / \mathrm{t}$. After the treatment of cyproconazole, the smallest number of infected grains was obtained when grains were treated at a dose 5.0 $\mathrm{g} / \mathrm{t}$ (80.0 \% of infected grains). The fungistatic effect of cyproconazole (C) and fludioxonil (F) was greatest when ratios of $\mathrm{C}: \mathrm{F}$ were $2.5: 10 ; 5: 10 ; 10: 2.5 ; 10: 5 ; 10: 10 \mathrm{~g} / \mathrm{t}$.
\end{abstract}

\section{Introduction}

Currently, there are various ways to protect plants from fungal diseases. However, the most popular and affordable means are fungicides. They are necessary for increasing plant productivity, but they have an adverse effect on the environment and on the plants [Ошибка! Источник ссылки не найден.]. Modern plant protection combines biological and socio-economic approaches. On the one hand, it is aimed to reduce damage of diseases and pests to plants. On the other hand, the cost of implementation of protection techniques should be lower than the resulting profit. Development of new products is aimed at efficiency of active substances (a.s.); preparation of the composition of several substances in such a way as to achieve the effect of mutual enhancement of action; selection of optimal doses of exposure. In addition, the objectives of cost reduction, composition optimization, and others are pursued [Ошибка! Источник ссылки не найден.].

Fludioxonil is a non-systemic fungicide, introduced in 1993 by Ciba-Geigy (now Syngenta). It is used for the treatment of crops (particularly cereals, fruits and vegetables, and ornamental plants; often in combination with another fungicide such as cyprodinil) [Ошибка! Источник ссылки не найден.]. It controls the following pests: Altemaria, Ascochyta, Aspergillus, Fusarium, Helminthosporium, Rhizoctonia and Penicillium spp., Tilletia [Ошибка! Источник ссылки не найден.]. It is toxic to fish and other aquatic organisms [Ошибка! Источник ссылки не найден.].
Its mode of action is to inhibit transport-associated phosphorylation of glucose, which reduces mycelial growth rate [Ошибка! Источник ссылки не найден.].

Cyproconazole is an agricultural fungicide of the class of azoles, used on cereal crops, coffee, sugar beet, fruit trees and grapes [Ошибка! Источник ссылки не найден.], on sod farms and golf courses and on wood as a preservative [Ошибка! Источник ссылки не найден.]. It was introduced to the market by then Sandoz in 1994 (which is Syngenta as of 2000). Cyproconazole inhibits demethylation, a particular step in the synthesis of a component of the fungal cell wall called sterol. This means it affects fungal growth, but not the fungal sporulation. This explains why it must be used when fungal growth is maximum, early in the infection, because in late infections fungal growth slows down and the agent is ineffective [Ошибка! Источник ссылки не найден.]. Cyproconazole is used against powdery mildew, rust on cereals and apple scab, and applied by air or on the ground to cereal crops, coffee, sugar beet, fruit trees and grapes [Ошибка! Источник ссылки не найден.]. It controls the following pests: Puccinia graminis, Puccinia spp., Pseudocercosporella herpotrichoides and Septoria species. It inhibits Septoria, Pyrenophora, Fusarium, Ustilago, Rhynchosporium, Bipolaris, Cercospora [Ошибка! Источник ссылки не найден.].

Objective of the research was to assess the efficiency of the joint application of the active ingredients of fungicides cyproconazole and fludioxonil, which are

\footnotetext{
* Corresponding author: nefedieva@,rambler.ru
} 
included in the preparation KingCombi (Agro Expert Group LLC).

\section{Materials and methods}

The objects of the study were wheat (Triticum $s p$. variety Julius) and barley (Hordeum sativum variety Gloria) grains (yield of 2017), which did not have pre-sowing treatments and were obviously infected.

Agarized Čapek nutrient medium was used. Before autoclaving, the detergent Triton (Triton X100) was added to the medium, because it limits the rate of linear growth of colonies and prevents the formation of abundant air mycelium. It does not affect the structure of mycelium in working concentration $2 \times 10^{-4}$. When using Triton X100, the colonies of fungi in the Petri dish nutrient medium do not merge for several weeks, so it affects the accuracy of the analysis results.

Autoclaving of the nutrient medium was performed at $1 \mathrm{~atm}$ for 30 minutes. Water, paper, glassware, metal objects were autoclaved at $2 \mathrm{~atm}$ for 60 minutes. Before sowing, the nutrient agar was cooled to $55^{\circ} \mathrm{C}$.

For surface sterilization, $10 \mathrm{~g}$ of grain samples were taken from the average sample and labelled. Samples of grains were placed in plastic containers with small holes that allow free circulation of liquids, but hold the grains. To remove surface spores, the surface of the grains was sterilized. Surface sterilization does not destroy the mycelium that infects the grain. The grains were thoroughly washed with running tap water, first with the addition of a detergent, and then with pure water. This allows washing away pieces of soil and other impurities. After that, the grain was subjected to surface sterilization.

Solution of sodium hypochlorite $(\mathrm{NaOCl}) 5 \%$ was used as sterilizing agents. The treatment was carried out for 5 minutes. After surface sterilization, the grains were thoroughly washed several times with sterile water.

In the laminar-box, the grains were taken with sterile tweezers, and dried on sterile filter paper. Dried sterile grains from the control sample were placed with sterile tweezers in Petri dishes with pre-poured and cooled nutrient medium to determine infection. We used 10 grains in each Petri dish at the same distance from each other.

The remaining dried sterile grains were processed by active substances (a.s.) of fungicides to analyse their fungicidal and fungistatic action by counting the infected grains, the number of colonies and their diameters in dynamics. Doses of cyproconazole and fludioxonil [Ошибка! Источник ссылки не найден.] were 0.25; $0.50 ; 1.0 \mathrm{mg} / 100 \mathrm{~g}$ of grains $(2.5 ; 5.0 ; 10.0 \mathrm{~g} / \mathrm{t}$ of grain, respectively). These ratios were $1 ; 2 ; 4$. Samples of 10 grains from each treated repeatation were placed on the surface of the agarized nutrient medium in Petri dishes.

Petri dishes with the analysed samples were kept in a thermostat in the dark at a temperature of $23-25^{\circ} \mathrm{C}$ for 7 days. They were viewed, and colonies of fungi that grew around the grains were counted. The diameter of the colonies was measured for samples treated with a.s.
The analysis of the species diversity of the composition of fungi for predicting the development of diseases and developing measures to limit their number was carried out at the genus level. The average infestation was calculated based on the infestation of grains from all samples. The standard deviation and statistical error were calculated.

This analysis was carried out on control sterile grains; their high level of infestation will allow assessing the effectiveness of a.s. of fungicides which were selected for the development of a combined fungicide preparation for pre-sowing treatment of grains [Ошибка! Источник ссылки не найден.].

\section{Results and discussion}

According to table 1, wheat grains were most infected by Fusarium fungi [Ошибка! Источник ссылки не найден.]. The infection rate was $97 \%$. Among the infected grains, fungi of the genus Alternaria [Ошибка! Источник ссылки не найден.] were identified in $77 \%$ of cases. To a lesser extent (17\%), the grains were affected by fungi of the genus Cladosporium [Ошибка! Источник ссылки не найден.]. Only $5 \%$ of the grains were infected with Helminthosporium [Ошибка! Источник ссылки не найден.] fungi.

Table 1. Analysis of infection of wheat and barley, $\mathrm{M} \pm \mathrm{m}$.

\begin{tabular}{|c|c|c|}
\hline Genus & $\begin{array}{c}\text { Rate of infected } \\
\text { grains of wheat, } \\
\mathbf{\%}\end{array}$ & $\begin{array}{c}\text { Rate of infected } \\
\text { grains of barley, } \\
\text { \% }\end{array}$ \\
\hline Fusarium & $97 \pm 3.3$ & $82 \pm 5.2$ \\
\hline Alternaria & $77 \pm 7.7$ & $42 \pm 5.0$ \\
\hline Cladosporium & $17 \pm 4.1$ & $2 \pm 1.7$ \\
\hline Helminthosporium & $5 \pm 3.6$ & $0 \pm 0.0$ \\
\hline
\end{tabular}

According to table 1, most of the barley grains (68\%) are infected with Fusarium fungi. To a lesser extent, $35 \%$ of grains are infected with fungi of the genus Alternaria and $2 \%$ of grains are infected with fungi of the genus Cladosporium. In general dynamics, barley grains are fewer infected and colonised as compared to wheat grains. This may indicate that they are more resistant to phytopathogenic fungi.

Fig. 1 and 2 present data for the 7 th day, when the largest changes were detected. 


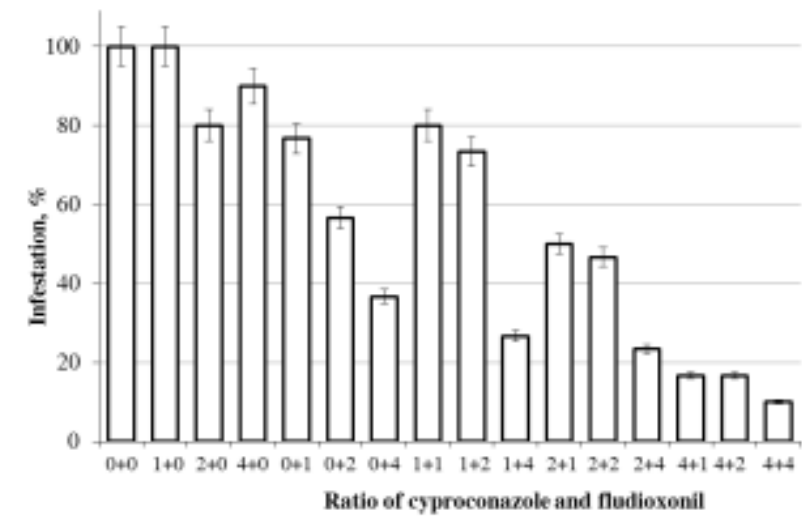

Fig. 1. The effect of ratio of cyproconazole and fludioxonil on the infestation of grains of wheat in 7 days of growth.

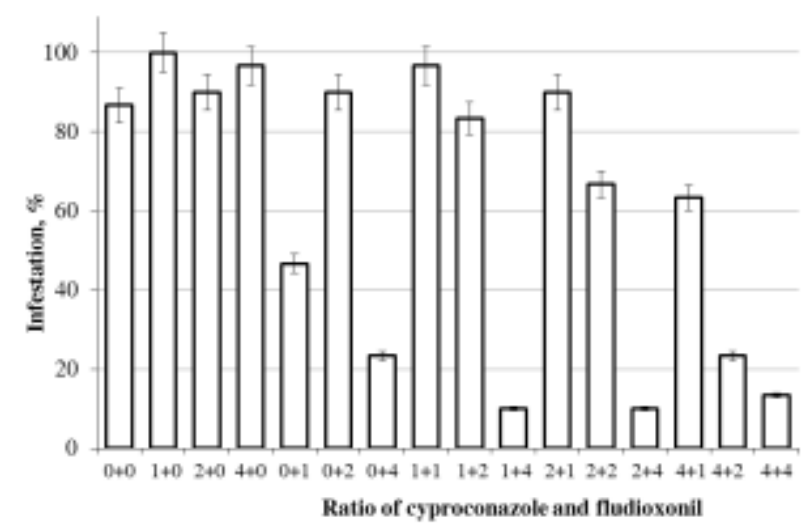

Fig. 2. The effect of ratio of cyproconazole and fludioxonil on the infestation of grains of barley in 7 days of growth.

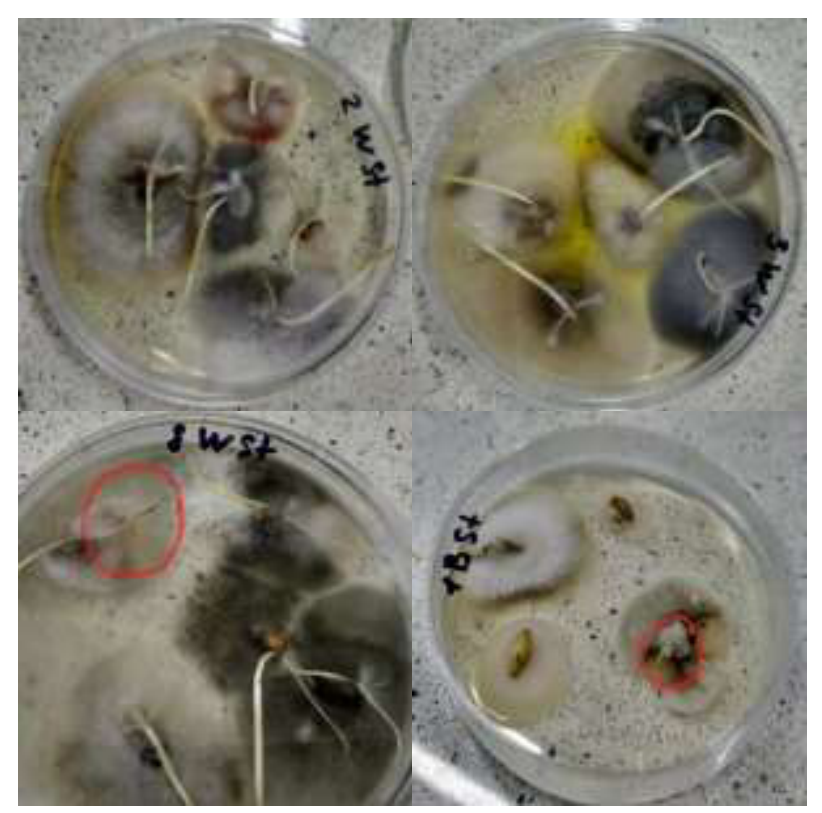

Fig. 3. Photos of infected seedlings.

All wheat grains treated with a.s. were infected less than the control ones. Analysis of the effect of individual a.s demonstrated that the fungi were more sensitive to fludioxonil, especially at doses of CF 0: $2(56.7 \%$ of infected grains) and CF 0:4 (36.7\% of infected grains). After the treatment of cyproconazole, the smallest number of infected grains was obtained when grains were treated at a dose of CF 2:0 (80.0\% of infected grains). Among the mixtures, the greatest fungistatic effect was obtained by combination of a.s. in the ratios CF 1:4 (26.7\% of infected grains), CF 2:4 (23.3\% of infected grains), CF $4: 1$ (16.7\% of infected grains), CF $4: 2(16.67 \%$ of infected grains) and CF $4: 4$ (10\% of infected grains).

Analysis of the influence of a.s. on barley grains demonstrated similar patterns with minor differences. After the treatment of fludioxonil, the smallest number of infected barley grains was obtained when grains were treated at a dose of CF 0:1 (46.7\% of infected grains) and $\mathrm{CF} \quad 0: 4 \quad(23.3 \%$ of infected grains). After the treatment of cyproconazole at the dose CF 2:0 (90.0\% of infected grains). The most effective mixtures were ratios of CF 1:4 (10.0\% of infected grains), CF 2:4 (10.0\% of infected grains), CF 4:2 (23.3\% of infected grains) and CF 4:4 (13.3\% of infected grains).

The results of this study showed that the grains were indeed significantly infected with phytopathogenic fungi, which allows us to get reliable data on the effectiveness of a.s. of fungicides. The fungistatic effect of fludioxonyl and ciproconazole was found to be particularly effective in the ratios of CF $1: 4$, CF $2: 4, C F$ 4:1, CF 4:2, and CF 4: 4. The conditions of this analysis (darkness) are aimed at evaluating the growth of fungi, not plants.

\section{References}

1. E.V. Baybakova, E.E. Nefed'eva, S.L. Belopukhov, Izvestiya vuzov, Prikladnaya himiya i biotekhnologiya, News of universities. Applied chemistry and biotechnology 6, 3, 57-64 (2016).

2. E.V. Baybakova, E.E. Nefed'eva, M.N. Belitskaya, I.R. Gribust, V.F. Zheltobriukhov, IOP Conf. Series: Earth and Environmental Science 315, 5 (2019).

3. K. Paranjape, G. Vasant, V.N. Krishnamurthy, S. Gowariker, The Pesticide Encyclopedia (CABI, 2014).

4. N.V. Berezina, Yu.I. Meshkov, Protection of Tulip pasture culture Greenhouses of Russia 1, 56-57 (2008).

5. PPDB: Pesticide Properties Electronic resource.. Available at: http://sitem.herts.ac.uk/aeru/ppdb/en/Reports/330.ht $\mathrm{m}$.

6. Joint FAO/WHO Meeting on Pesticide Residues, Cyproconazole 2010, Food and Agriculture Organization of the United Nations (FAO), 766-938 (2011).

7. Chromated Copper Arsenate (CCA): Cyproconazole - An Alternative to CCA EPA (2014).

8. P. Esker, R. Proost, Fungicide resistance management in corn, soybean, and wheat (University of Wisconsin extension service, 2010).

9. N.M. Golyshin, Fungicides (Moscow Kolos, 1993).

10. E.V. Baibakova, E.E. Nefed'eva, M. SuskaMalawska, M. Wilk, G.A. Sevriukova, V.F. Zheltobriukhov, Annual Research \& Review in Biology 32, 3, 1-16 (2019). 
11. J.L. Nistrup, O.R. Peter, H.T. Marten, Occurrence and avoidance of fungicide resistance in cereal diseases, 235-259 (2018).

12. Fusarium oxysporum: Mycobank Database Electronic resource.. Available at: http://www.mycobank.org/

Biolomics.aspx ?Table=Mycobank\&MycoBankNr $=218$ 372

13. Alternaria alternata: Mycobank Database Electronic resource.. Available at: http://www.mycobank.org/MB/119834.

14. Cladosporium: Mycobank Database Electronic resource.. Available at:

http://www.mycobank.org/BioloMICSDetails.aspx? $\mathrm{Rec}=33538$.

15. Helminthosporium: Mycobank Database Electronic resource.. Available at: http://www.mycobank.org/BioloMICSDetails.aspx? $\mathrm{Rec}=56683$. 